$\mathrm{DE}$

M E D I C I N A

T R O P I C A L

$\mathrm{DE}$

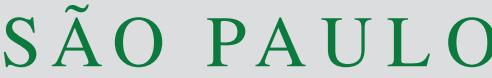

JOURNAL OF THE SÃO PAULO INSTITUTE OF TROPICAL MEDICINE

${ }^{1}$ Universidade do Estado de Mato Grosso, Faculdade de Ciências da Saúde, Departamento de Medicina, Cáceres, Mato Grosso, Brazil

2Universidade do Estado de Mato Grosso, Faculdade de Ciências da Saúde, Departamento de Enfermagem, Cáceres, Mato Grosso, Brazil

${ }^{3}$ Universidade do Estado de Mato Grosso, Faculdade de Ciências Agrárias e Biológicas, Programa de Pós-Graduação em Ciências Ambientais, Cáceres, Mato Grosso, Brazil

${ }^{4}$ Centro de Excelência do Instituto Joanna Briggs, Centro Brasileiro para o Cuidado à Saúde Informado por Evidências, São Paulo, São Paulo, Brazi

${ }^{5}$ Faculdade do Pantanal, Cáceres, Mato Grosso, Brazil

Correspondence to: Omar Ariel Espinosa Faculdade do Pantanal, Av. São Luiz, 2522 CEP 78200-000, Cáceres, MT, Brazil Tel: +55 65 99999-5940

E-mail: omar.espinosa@ fapan.edu.br

Received: 18 June 2020

Accepted: 22 June 2020

\section{Chronic heart diseases as the most prevalent comorbidities among deaths by COVID-19 in Brazil}

Julianne Pachiega ${ }^{(1)}$, Alexandre José dos Santos Afonso ${ }^{(1)}$, Géssica Thaís Sinhorin ${ }^{(1)}$, Bianca Teshima de Alencar ${ }^{\circledR 2}$, Marta dos Santos Miranda de Araújo $^{\left({ }^{3}\right.}$, Fabiana Gulin Longhi ${ }^{(1)}$, Andernice dos Santos Zanetti ${ }^{\left({ }^{\circ}\right.}$, Omar Ariel Espinosa ${ }^{\circ}$

\section{ABSTRACT}

Age, sex and presence of comorbidities are risk factors associated with COVID-19. Hypertension, diabetes and heart disease are the most common comorbidities in patients with COVID-19. The objective of this study was to estimate the prevalence of patients with comorbidities who died of COVID-19 in Brazil. Searches of data were carried out on the official pages of the 26 State health departments and the federal district. The random-effect method was used to calculate the prevalence of patients with comorbidities who died. From the beginning of the pandemic in Brazil until May 20, 2020, 276,703 cases of COVID-19 were notified in Brazil, $6.4 \%$ died, $58.6 \%$ of whom were male. The prevalence of comorbidities among deaths was $83 \%$ (95\% CI: 79 - 87), with heart disease and diabetes being the most prevalent. To our knowledge, this study represents the first large analysis of cases of patients with confirmed COVID-19 in Brazil. There is a high prevalence of comorbidities (83\%) among patients who died from COVID-19 in Brazil, with heart disease being the most prevalent. This is important considering the possible secondary effects produced by drugs such as hydroxychloroquine.

KEYWORDS: COVID-19. Prevalence. Deaths. Comorbidities. Brazil. Heart disease. Diabetes.

\section{INTRODUCTION}

The coronavirus disease 2019 (COVID-19) pandemic has infected more than seven million people worldwide in 216 countries, and, until Jun 16, 2020, it had caused over four hundred thousand deaths ${ }^{1}$. Its etiological agent is the severe acute respiratory syndrome coronavirus 2 (SARS-CoV-2), transmitted by contact with an infected person or contaminated fluids ${ }^{2,3}$.

A multicenter cohort study showed that gender and advanced age are significantly correlated with COVID-19 and these findings are consistent with the higher incidence among older people and $\mathrm{men}^{4}$. Another study observed that the presence of any comorbidity increases the patient's risk of developing respiratory distress, possibly leading to an intensive care unit (ICU) hospitalization and/or death $^{5,6}$. Cardiovascular diseases, diabetes, hypertension, and chronic obstructive pulmonary disease are among the most prevalent comorbidities in COVID-19 cases $^{7}$.

In Brazil, the first confirmed case of COVID-19 was reported on February 26, $2020^{8}$, and the first known death was reported 20 days later, on March 17. Until 
June 21 , the country had confirmed $1,073,376$ cases and 50,182 deaths, with an incidence of 5.08 cases per million inhabitants.

This study aimed to estimate the prevalence of patients with comorbidities that died of COVID-19 in the Brazilian Federative Units.

\section{METHODS}

Data were extracted from the bulletin on the epidemiological situation of COVID-19, made available by each of the 26 Brazilian States and the Federal District, on their official websites. The obtained data were evaluated according to the following variables: confirmed cases, ICU hospitalizations and deaths. The epidemiological and clinical profiles of the death's cases were also described, considering sex, age, and the presence and type of comorbidities, respectively.

Because not all States reported the presence of comorbidities in fatal cases, the random-effects model to estimate the pooled prevalence of comorbidities in deaths and their respective confidence intervals (CI) of $95 \%$, was used. The heterogeneity of prevalence was analyzed by State using the Higgins test $\left(\mathrm{I}^{2}\right)$, which presents the percentage of variation across them. These analyses were performed using the Stata statistical software, version 12 (Stata Corp LLC, Texas, USA).

\section{RESULTS}

Data collection from the official websites of each State Health Department took place from the beginning of the pandemic in Brazil to May 20, 2020. During this period, we found 276,703 reported cases of COVID-19, among which $11,278(4.8 \%)$ were admitted to ICU, and 17,752 (6.4\%) cases resulted in deaths.

When analyzing ICU hospitalization percentage by State, Rio de Janeiro (23.3\%) and Minas Gerais (19.6\%) were the States with the highest prevalences. (Table 1) The States with the highest death percentages were: Rio de Janeiro (10.7\%), Para (9.4\%), Sao Paulo (7.8\%), Pernambuco (8.1\%), Amazonas (6.9\%) and Parana (5.2\%). Table 1 shows the percentages for each State.

Regarding the epidemiological profile of fatal cases, 22 States segregated a total of 7,531 cases by sex, of which $58.6 \%$ were male and $41.4 \%$ female. The age of the death cases was reported only in epidemiological bulletins of 25 States. From 17,752 cases of death, only in 14,728 $(83 \%)$ the age was reported, the population over 60 years old was the most affected (71.4\%) (Table 1). Conversely, the clinical profile was only reported in 2,116 deaths $(12 \%)$ from 15 States, 1,768 of which presented comorbidities, resulting in an $83 \%$ prevalence (95\% CI: $79-87$ ) (Table 1).

The clinical descriptions of the comorbidities in the death cases were extracted from the epidemiological bulletins of each State, which reported diseases grouped according to: Chronic Heart Diseases, Diabetes, Chronic Lung Diseases (including Chronic Obstructive Pulmonary Disease and asthma), Chronic Kidney Diseases, Stroke, Hypertension, Obesity, Immunosuppressive Diseases, Chronic Liver Diseases, Cancer, Digestive System Diseases, Pneumonia, Hematological diseases, Tuberculosis, Metabolic Diseases (different than diabetes), Smoking habit, Others (not specified).

Among the cases of death, that showed one or more previous diseases, a total of 14,737 comorbidities were recorded. The most prevalent comorbidities found were: $35 \%$ chronic heart diseases, $28.7 \%$ diabetes, $8.2 \%$ chronic lung diseases (including asthma and Chronic Obstructive Pulmonary Disease), 5.9\% kidney diseases, $5.3 \%$ stroke, $5.1 \%$ hypertension, $4.4 \%$ obesity, and 3.8\% immunosuppressive diseases (Table 2).

\section{DISCUSSION}

To our knowledge, this study represents the first large analysis of cases of sequentially patients with confirmed COVID-19 in Brazil. By June 21, 2020, Brazil was the second country in number of confirmed cases of COVID-19, reporting over a million cases of confirmed COVID-19 and our analysis included approximately a quarter of these cases. As in different parts of the world, a higher prevalence in men and people aged 60 years or in elderly people were found among deaths by COVID-199-11.

We found that $4.8 \%$ of COVID-19 patients were admitted to ICU, a percentage comparable with a previous study conducted in the United States of America (USA) that analyzed 74,439 COVID-19 patients, among whom $1.4 \%$ required $\mathrm{ICU}^{12}$. Data collected from 138 patients in China showed that $26 \%$ were admitted to ICUs ${ }^{13}$. Thus, States such as Rio de Janeiro and Minas Gerais, with the highest hospitalization percentages in the country $(23.3 \%$ and $19.6 \%$, respectively), should strengthen measures to avoid the collapse of their hospitals intensive care units.

By June 21, 2020, Brazil has exceeded 50,000 deaths, a mark, so far, reached by only two countries worldwide. Considering that, Rio de Janeiro, Para, Sao Paulo, Pernambuco, and Amazonas, which present higher percentages than that calculated for the overall country, represent a great national concern. When dealing with the COVID-19 pandemic, mortality, as well as establishing priorities for controlling it, is the most important concern. 
Table 1 - Distribution of epidemiological and clinical variables from confirmed and deaths cases of COVID-19, according to the State of Brazil, until May 20, 2020.

\begin{tabular}{|c|c|c|c|c|c|c|c|c|c|c|}
\hline State & Confirmed & $\begin{array}{c}\text { ICUs } \\
\mathrm{N}\end{array}$ & $\begin{array}{c}\text { ICUs } \\
\%\end{array}$ & $\begin{array}{c}\text { Deaths } \\
\mathrm{N}\end{array}$ & $\begin{array}{c}\text { Deaths } \\
\%\end{array}$ & $\begin{array}{l}\text { Deaths by } \\
\text { age }\end{array}$ & $\begin{array}{c}\text { Deaths } \\
>60 \text { years } \\
\mathrm{N}\end{array}$ & $\begin{array}{c}\text { Deaths } \\
>60 \text { years } \\
\%\end{array}$ & $\begin{array}{l}\text { Prevalence of } \\
\text { comorbidities } \\
\text { among deaths }\end{array}$ & $95 \% \mathrm{Cl}$ \\
\hline$A C$ & 2,234 & 16 & 0.7 & 67 & 3.0 & 67 & 42 & 62.7 & 76 & $65-85$ \\
\hline$A L$ & 4,031 & N.S. & N.S. & 221 & 5.5 & 221 & 145 & 65.6 & N.S. & N.S. \\
\hline$A P$ & 4,310 & 80 & 1.9 & 136 & 3.2 & 0 & 0 & 0.0 & N.S. & N.S. \\
\hline AM & 20,913 & 190 & 0.9 & 1,433 & 6.9 & 0 & 0 & 0.0 & N.S. & N.S. \\
\hline $\mathrm{BA}$ & 8,881 & N.S. & N.S. & 312 & 3.5 & 312 & 210 & 67.3 & 86 & $82-89$ \\
\hline CE & 28,092 & 646 & 2.3 & 1,312 & 4.7 & 750 & 378 & 28.8 & N.S. & N.S. \\
\hline DF & 4,618 & 121 & 2.6 & 66 & 1.4 & 62 & 48 & 72.7 & 89 & $80-95$ \\
\hline ES & 4,412 & N.S. & N.S. & 172 & 3.9 & 172 & 128 & 74.4 & N.S. & N.S. \\
\hline GO & 1,114 & 87 & 7.8 & 51 & 4.6 & 51 & 37 & 72.5 & 65 & $51-76$ \\
\hline MA & 15,114 & N.S. & N.S. & 634 & 4.2 & 634 & 476 & 75.1 & 86 & $83-89$ \\
\hline MT & 1,695 & 48 & 2.8 & 32 & 1.9 & 32 & 18 & 56.3 & 91 & $76-97$ \\
\hline MS & 693 & 11 & 1.6 & 17 & 2.5 & 17 & 13 & 76.5 & 94 & $73-99$ \\
\hline MG & 5,286 & 1,038 & 19.6 & 177 & 3.3 & 177 & 133 & 75.1 & 90 & $84-93$ \\
\hline PA & 18,929 & 304 & 1.6 & 1,778 & 9.4 & 1,778 & 1,247 & 70.1 & N.S. & N.S. \\
\hline PB & 5,838 & N.S. & N.S. & 230 & 3.9 & 230 & 145 & 63.0 & N.S. & N.S. \\
\hline PR & 2,616 & 78 & 3.0 & 137 & 5.2 & 137 & 94 & 68.6 & 66 & $57-73$ \\
\hline PE & 22,560 & 229 & 1.0 & 1,834 & 8.1 & 1,834 & 1,316 & 71.8 & N.S. & N.S. \\
\hline PI & 2,852 & 139 & 4.9 & 91 & 3.2 & 91 & 67 & 73.6 & 90 & $82-95$ \\
\hline RJ & 30,372 & 7,084 & 23.3 & 3,237 & 10.7 & 3,237 & 2,333 & 72.1 & N.S. & N.S. \\
\hline $\mathrm{RN}$ & 3,796 & 137 & 3.6 & 170 & 4.5 & 169 & 110 & 64.7 & 81 & $74-86$ \\
\hline RS & 4,972 & 233 & 4.7 & 139 & 2.8 & 139 & 118 & 84.9 & 94 & $88-97$ \\
\hline RO & 2,499 & N.S. & N.S. & 90 & 3.6 & 43 & 28 & 31.1 & 82 & $73-89$ \\
\hline $\mathrm{RR}$ & 3,296 & N.S. & N.S. & 64 & 1.9 & 64 & 36 & 56.3 & 47 & $35-59$ \\
\hline SC & 5,499 & 107 & 1.9 & 94 & 1.7 & 94 & 67 & 71.3 & N.S. & N.S. \\
\hline SP & 65,995 & 521 & 0.8 & 5,147 & 7.8 & 4,343 & 3,315 & 64.4 & N.S. & N.S. \\
\hline SE & 4,277 & 178 & 4.2 & 69 & 1.6 & 74 & 47 & 68.1 & 93 & $84-97$ \\
\hline TO & 1,809 & 31 & 1.7 & 42 & 2.3 & 42 & 5 & 11.9 & N.S. & N.S. \\
\hline Total & 276,703 & 11,278 & 4.1 & 17,752 & 6.4 & 14,770 & 10,551 & 71.4 & 83 & $79-87$ \\
\hline
\end{tabular}

Source: The epidemiological and clinical profiles of confirmed and deaths cases of COVID-19 were obtained through the bulletin information on the epidemiological situation of COVID-19, which each Brazilian State makes available on its official websites. ICUs = Patients admitted to intensive care units; $95 \% \mathrm{CI}=95 \%$ confidence interval; N.S. = Not specified. AC (Acre); AL (Alagoas); AP (Amapa); AM (Amazonas); BA (Bahia); CE (Ceara); DF (Distrito Federal); ES (Espirito Santo); GO (Goias); MA (Maranhao); MT (Mato Grosso); MS (Mato Grosso do Sul); MG (Minas Gerais); PA (Para); PB (Paraiba); PR (Parana); PE (Pernambuco); PI (Piaui); RJ (Rio de Janeiro); RN (Rio Grande do Norte); RS (Rio Grande do Sul); RO (Rondonia); RR (Roraima); SC (Santa Catarina); SP (Sao Paulo). SE (Sergipe); TO (Tocantins).

The capacity of the healthcare system thus becomes a major issue, especially considering that the number of confirmed cases in communities is rapidly increasing, as is the case in Brazil.

The pooled prevalence of comorbidities in deaths by COVID-19 in Brazil was 83\% (95\% CI: $79-87$ ). Previous studies conducted in Korea (90.7\%) and China (68.2\%) warned about a higher prevalence of severe acute respiratory syndrome caused by SARS-CoV-2 among patients with comorbidities ${ }^{11,14}$. They also point hypertension, cardiovascular diseases, and diabetes as the main comorbidities among deaths by the disease. Several studies suggest that hypertension is the most common comorbidity in COVID-19 patients $^{15}$. Likewise, a metaanalysis carried out recently by our team showed that hypertension is the most prevalent comorbidity among deaths from COVID-19' followed by diabetes and chronic heart diseases ranking third ${ }^{16}$. Now, in Brazil we found that the main comorbidities among deaths are chronic heart diseases and diabetes. The third most common comorbidity were the chronic lung diseases, followed by chronic kidney diseases, stroke, hypertension, obesity and immunosuppressive diseases which may include HIV infection and organ transplant patients. 
Table 2 - Percentage of comorbidities reported among deaths due to COVID-19 from May 9 to 20, 2020 in Brazil.

\begin{tabular}{|c|c|c|}
\hline Comorbidities & Total & $\%$ \\
\hline Chronic Heart Diseases & 5,170 & 35.1 \\
\hline Diabetes & 4,233 & 28.7 \\
\hline Chronic Lung Diseases & 848 & 8.2 \\
\hline Chronic Kidney Diseases & 871 & 5.9 \\
\hline Stroke & 786 & 5.3 \\
\hline Hypertension & 753 & 5.1 \\
\hline Obesity & 654 & 4.4 \\
\hline Immunosuppressive Diseases & 567 & 3.8 \\
\hline Chronic Liver Diseases & 157 & 1.1 \\
\hline Cancer & 85 & 0.6 \\
\hline Digestive System Diseases & 3 & 0.02 \\
\hline Pneumonia & 7 & 0.0 \\
\hline Hematological diseases & 24 & 0.2 \\
\hline Tuberculosis & 4 & 0.03 \\
\hline Metabolic Diseases & 50 & 0.3 \\
\hline Smoking habit & 8 & 0.1 \\
\hline Others & 162 & 1.1 \\
\hline Total & 14,737 & 100 \\
\hline
\end{tabular}

Source: Clinical profiles of confirmed and deaths cases by COVID-19. were obtained through the bulletin information about the epidemiological situation of COVID-19, which each Brazilian state makes available on its official websites.

The epidemiological bulletins of each State do not specify what were the chronic heart diseases of patients who died from COVID-19, although this group may include patients with coronary heart disease, arrhythmias, infarction, patients with pacemakers and others. Our results showed that this group of comorbidities was the most important in the population studied, and this is an important finding, because the Ministry of Health defends the use of hydroxychloroquine for treating COVID-19. A recent study claims that some cardiac manifestations, such as cardiac arrhythmias, and even conduction disorders without repercussion, may represent the initial manifestations of toxicity related to chloroquine or hydroxychloroquine ${ }^{17}$. Therefore, the use of these drugs can lead to serious complications and even death in patients with previous heart disease. On the other hand, the use of these drugs as post exposure prophylaxis (PEP), has also proved unsuccessful ${ }^{18}$.

Some difficulties to develop this study were found. Firstly, not every Health Department updates their epidemiological bulletins daily, so the updating of data on a daily basis was unfeasible. Secondly, the epidemiological bulletins were not standardized, not all of them provide epidemiological data such as age, nor clinical data such as the presence of comorbidities, which impaired the collection of complete data. Thirdly, many epidemiological bulletins provide information only as graphics and the absolute numbers were lacking, hampering data replication. Finally, each Secretariat reported different age groups, which impaired the comparisons among them.

We concluded that there is a high prevalence of comorbidities among deaths by COVID-19, affecting mainly men aged over 60 years. The group of chronic heart diseases and diabetes were the main comorbidities among these patients and this is relevant considering the possible adverse effects produced by drugs such as hydroxychloroquine. On the other hand, we recommend conducting studies based on medical records analyzes, with the purpose of knowing specifically the proportion of each heart disease in patients affected by COVID-19.

Acknowledging such factors may help to better defining the risks of death among these COVID-19 patients, enabling a more targeted and specific approach to avoid probable deaths. In a scenario without effective antivirals or vaccines available, governments should apply continuous countermeasures for different pandemic situations to reduce mortality, especially in States with high percentages of ICU hospitalization and deaths.

\section{AUTHORS' CONTRIBUTIONS}

JP, AJSA, GTS, BTA, MSMA and FGL contributed to data collection and analysis, and drafting the first version of the manuscript; ADSZ and OAE contributed to study conception and design, data analysis and interpretation, and writing the final version of the manuscript. All authors approved the final version of the manuscript and declared themselves responsible for all aspects of the work, guaranteeing their accuracy and integrity.

\section{CONFLICT OF INTERESTS}

The authors declare no conflict of interests.

\section{REFERENCES}

1. World Health Organization. Coronavirus disease 2019 (COVID-19): situation report - 124. [cited 2020 Jun 22]. Available from: https://www.who.int/docs/default-source/ coronaviruse/situation-reports/20200523-covid-19-sitrep-124. pdf?sfvrsn=9626d639_2

2. Gorbalenya AE, Baker SC, Baric RS, de Groot RJ, Drosten C, Gulyaeva AA, et al. The species severe acute respiratory 
syndrome-related coronavirus: classifying 2019-nCoV and naming it SARS-CoV-2. Nat Microbiol. 2020;5:536-44.

3. Chan JF, Yuan S, Kok KH, To KK, Chu H, Yang J, et al. A familial cluster of pneumonia associated with the 2019 novel coronavirus indicatingperson-to-person transmission: a study of a family cluster. Lancet. 2020;395:514-23.

4. Cai H. Sex difference and smoking predisposition in patients with COVID-19. Lancet Respir Med. 2020;8:e20.

5. Chen N, Zhou M, Dong X, Qu J, Gong F, Han Y, et al. Epidemiological and clinical characteristics of 99 cases of 2019 novel coronavirus pneumonia in Wuhan, China: a descriptive study. Lancet. 2020;395:507-13.

6. Wang D, Hu B, Hu C, Zhu F, Liu X, Zhang J, et al. Clinical characteristics of 138 hospitalized patients with 2019 novel coronavirus-infected pneumonia in Wuhan, China. JAMA. 2020;323:1061-9.

7. Yang J, Zheng Y, Gou X, Pu K, Chen Z, Guo Q, et al. Prevalence of comorbidities and its effects in coronavirus disease 2019 patients: a systematic review and meta-analysis. Int J Infect Dis. 2020;94:91-5.

8. Brasil. Ministério da Saúde. Secretaria de Vigilância em Saúde. Boletim Epidemiológico Especial COE-COVID19. Brasília: Ministério da Saúde; 2020. [cited 2020 Jun 22]. Available from: https://portalarquivos.saude.gov.br/images/pdf/2020/ Apri1/27/2020-04-27-18-05h-BEE14-Boletim-do-COE.pdf

9. Du RH, Liu LM, Yin W, Wang W, Guan LL, Yuan ML, et al. Hospitalization and critical care of 109 decedents with COVID-19 pneumonia in Wuhan, China. Ann Am Thorac Soc. 2020 In Press.

10. Chen T, Dai Z, Mo P, Li X, Ma Z, Song S, et al. Clinical characteristics and outcomes of older patients with coronavirus disease 2019 (COVID-19) in Wuhan, China (2019): a singlecentered, retrospective study. J Gerontol A Biol Sci Med Sci. 2020:glaa089 In Press.
11. Korean Society of Infectious Diseases, Korea Centers for Disease Control and Prevention. Analysis on 54 mortality cases of coronavirus disease 2019 in the Republic of Korea from January 19 to March 10, 2020. J Korean Med Sci. 2020;35:e132.

12. CDC COVID-19 Response Team. Preliminary estimates of the prevalence of selected underlying health conditions among patients with coronavirus disease 2019 - United States, February 12-March 28, 2020. MMWR Morb Mortal Wkly Rep. 2020;69:382-6.

13. Wang D, Hu B, Hu C, Zhu F, Liu X, Zhang J, et al. Clinical characteristics of 138 hospitalized patients with 2019 novel coronavirus-infected pneumonia in Wuhan, China. JAMA. 2020;323:1061-9.

14. Du Y, Tu L, Zhu P, Mu M, Wang R, Yang P, et al. Clinical features of 85 fatal cases of COVID-19 from Wuhan: a retrospective observational study. Am J Respir Crit Care Med. 2020;201:1372-9.

15. Wang B, Li R, Lu Z, Huang Y. Does comorbidity increase the risk of patients with COVID-19: evidence from meta-analysis. Aging (Albany NY). 2020;12:6049-57.

16. Espinosa OA, Zanetti AS, Antunes EF, Longhi FG, Matos TA, Battaglini PF. Prevalence of comorbidities in patients and mortality cases affected by SARS-CoV2: a systematic review and metaanalysis. Rev Inst Med Trop Sao Paulo. 2020;62:e43.

17. Chatre C, Roubille F, Vernhet H, Jorgensen C, Pers YM. Cardiac complications attributed to chloroquine and hydroxychloroquine: a systematic review of the literature. Drug Saf. 2018;41:919-31.

18. Boulware DR, Pullen MF, Bangdiwala AS, Pastick KA, Lofgren SM, Okafor EC, et al. A randomized trial of hydroxychloroquine as postexposure prophylaxis for Covid-19. N Engl J Med. 2020 In Press. 